\title{
Coincidental resemblances among coral reef fishes from different oceans
}

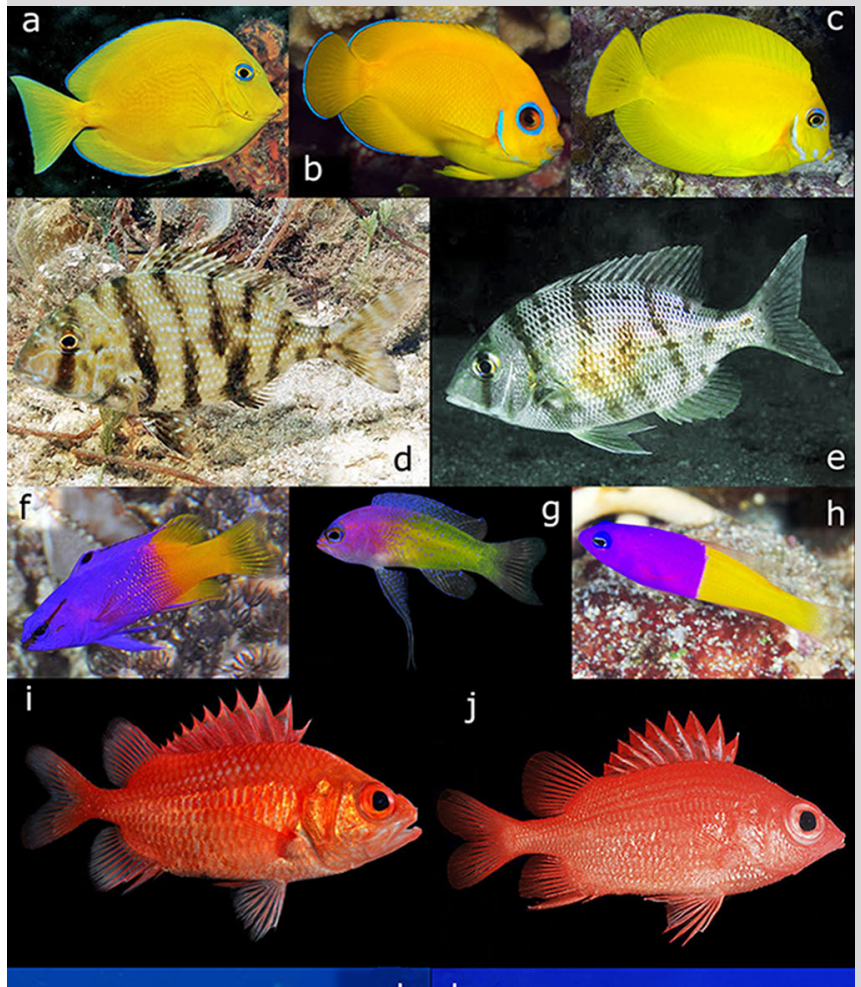

k I

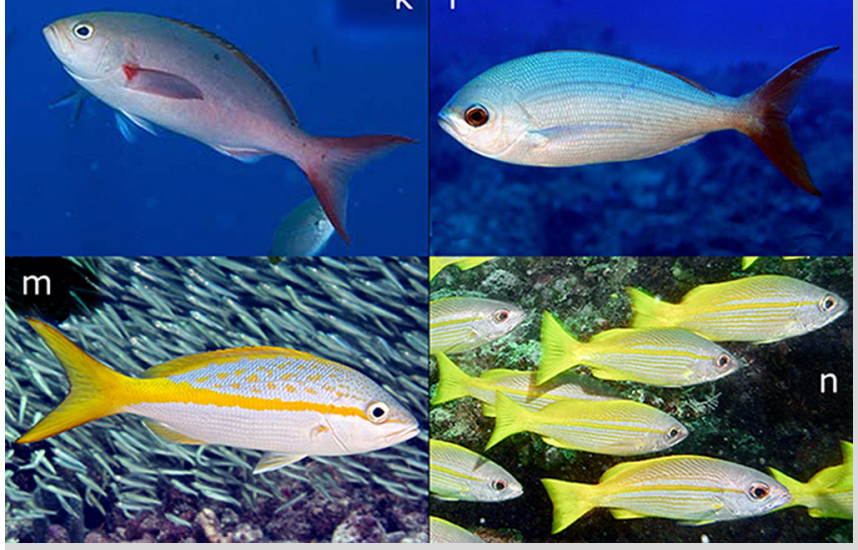

In mimicry, natural selection, through the actions of the mimicry target, matches the mimic's appearance to that of its model (Wickler 1968). Mimicry involving precise resemblances between species is common in terrestrial and marine organisms and occurs, infrequently, among coral reef fishes. Behavioral associations between approximately similar species of such fishes, which are more common, often are assumed to be mimetic because they (could) benefit one or both protagonists. However, such associating species may have independently (i.e., convergently) evolved similar appearances before the association developed. Such pseudo-mimetic relationships could develop when look-alike species have similar patterns of habitat use, and after being attracted by the similarity of the other, one learns of benefits from associating with it (Robertson 2013). Figure 1 shows six groups of lookalike species with similar habitat usage. The within-group resemblance in each case must be due to convergence rather than mimicry because they evolved in different oceans. These examples illustrate the necessity for careful consideration of competing hypotheses about the origins of morphological similarities and behavioral associations among coral reef fishes, although distinguishing pseudo-mimicry from the real thing will not be easy in many cases.

Fig. 1 Individuals that comprise six groups of look-alike species with similar habitat usage: Group 1 (a-c), Group 2 (d, e), Group $3(\mathbf{f}-\mathbf{h})$, Group $4(\mathbf{i}, \mathbf{j})$, Group 5 (k, l), and Group $6(\mathbf{m}, \mathbf{n})$. Most images are artificially lit, and members of each group likely are more similar (to human observers at least) under natural lighting. a Acanthurus coeruleus, juvenile (Acanthuridae; Atlantic), H Ramirez; b Centropyge flavissima (Pomacanthidae; Indo-Pacific), J. Johnson; c Acanthurus pyroferus, juvenile (Acanthuridae; Indo-Pacific), www.ryanphotographic.com-this species is included for comparison as it is thought to mimic (b) C. flavissima (Eagle and Jones 2004). d Calamus arctifrons (Sparidae; Atlantic), G Edgar; e Gymnocranius griseus (Lethrinidae; Indo-Pacific), Izuzuki. f Gramma loreto (Grammatidae; Atlantic), DR Robertson; g Lipogramma klayi (Grammatidae; Atlantic), DR Robertson-this species and (f) $G$. loreto co-occur and use similar habitats, but, because they have different depth ranges (www.stri.org/sfgc), likely are not involved in a mimetic relationship; h Pictichromis paccagnella (Pseudochromidae; Indo-Pacific), M Rosenstein. i Corniger spinosus (Holocentridae; Atlantic), DR Robertson; j Sargocentron iota (Holocentridae; Pacific), J Randall. k Paranthias furcifer (Serranidae; Atlantic), M Rosenstein; I Paracaesio sordida (Lutjanidae; Indo-Pacific), D Pollack. m Ocyurus chrysurus (Lutjanidae; Atlantic), C Estape; $\mathbf{n}$ Lutjanus lutjanus (Lutjanidae; Indo-Pacific), B Dupont

\section{References}

Wickler W (1968) Mimicry in plants and animals. McGraw Hill, New York Robertson DR (2013) Who resembles whom? Mimetic and coincidental look-alikes among tropical reef fishes. PLoS One 8:e54939 Eagle JV, Jones GP (2004) Mimicry in coral reef fishes: ecological and behavioural responses of a mimic to its model. J Zool 264:33-43

D. R. Robertson ( $\square)$

Smithsonian Tropical Research Institute, Balboa, Panama

e-mail: drr@stri.org 